\title{
Group awareness tools: It's what you do with it that matters
}

Citation for published version (APA):

Janssen, J., Erkens, G., \& Kirschner, P. A. (2011). Group awareness tools: It's what you do with it that matters. Computers in Human Behavior, 27(3), 1046-1058. https://doi.org/10.1016/j.chb.2010.06.002

DOI:

10.1016/j.chb.2010.06.002

Document status and date:

Published: 01/05/2011

Document Version:

Peer reviewed version

Document license:

CC BY-SA

Please check the document version of this publication:

- A submitted manuscript is the version of the article upon submission and before peer-review. There can be important differences between the submitted version and the official published version of record. People interested in the research are advised to contact the author for the final version of the publication, or visit the DOI to the publisher's website.

- The final author version and the galley proof are versions of the publication after peer review.

- The final published version features the final layout of the paper including the volume, issue and page numbers.

Link to publication

\section{General rights}

Copyright and moral rights for the publications made accessible in the public portal are retained by the authors and/or other copyright owners and it is a condition of accessing publications that users recognise and abide by the legal requirements associated with these rights.

- Users may download and print one copy of any publication from the public portal for the purpose of private study or research.

- You may not further distribute the material or use it for any profit-making activity or commercial gain

- You may freely distribute the URL identifying the publication in the public portal.

If the publication is distributed under the terms of Article 25fa of the Dutch Copyright Act, indicated by the "Taverne" license above, please follow below link for the End User Agreement:

https://www.ou.nl/taverne-agreement

Take down policy

If you believe that this document breaches copyright please contact us at:

pure-support@ou.nl

providing details and we will investigate your claim.

Downloaded from https://research.ou.nl/ on date: 26 Apr. 2023 
Running head: Using Group Awareness Tools

GROUP AWARENESS TOOLS: IT'S WHAT YOU DO WITH IT THAT MATTERS Jeroen Janssen $^{\mathrm{a}}$, Gijsbert Erkens ${ }^{\mathrm{a}}$, Paul Kirschner ${ }^{\mathrm{b}}$

${ }^{a}$ Research Centre Learning in Interaction, Utrecht University, The Netherlands

${ }^{\mathrm{b}}$ Centre for Learning Sciences and Technologies, Open University, The Netherlands

Address correspondence to:

Jeroen Janssen

Research Centre Learning in Interaction

Utrecht University

P.O. Box 80140

3508 TC Utrecht, The Netherlands

Tel.: +31302534798

E-mail: J.J.H.M.Janssen@uu.nl 
Abstract

This study examined the effect of using a group awareness tool on online collaboration. Furthermore, we examined whether the effect of using a group awareness tool on online collaboration is mediated by group awareness (i.e., students' awareness of their group members' levels of participation). To answer these questions, we determined how often and how long 107 secondary education students used the Participation-tool (PT), a group awareness tool designed to visualize group members’ relative contribution to the online collaborative process. Our analyses show that duration of PT use (how long students displayed the tool on their screens) significantly predicted group members' participation in the online dialogue, their participation when writing collaborative texts, equality of participation within the group, and coordination and regulation of activities in the relational space (i.e., discussing the collaboration process with group members). No effect of using the PT on group performance was found. Mediation analyses showed that the effect of using the PT is only partially mediated by group awareness: an indirect effect of using the PT, via enhanced group awareness, on student participation during chat discussions and the collaborative writing process was found. 
GROUP AWARENESS TOOLS: IT'S WHAT YOU DO WITH IT THAT MATTERS

\section{INTRODUCTION}

Although computer-supported collaborative learning (CSCL) has been identified as a promising educational approach, the research on the effectiveness of CSCL and the processes that take place during CSCL demonstrate that the collaboration in these environments is not always effective and efficient. These problems may include conflicts between group members (e.g., Hobman, Bordia, Irmer, \& Chang, 2002), free riding behavior and unequal participation (e.g., Fjermestad, 2004). Some problems however, may be unique to CSCL environments or may be exacerbated in these environments, such as difficulties coordinating one's actions with other group members’ actions (Baker, Greenberg, \& Gutwin, 2001; Ellis, Gibbs, \& Rein, 1992; Erkens, Jaspers, Prangsma, \& Kanselaar, 2005). These coordination problems, whether they occur in the content space (i.e., efforts aimed at problem solving, such as exchange of information or discussion of answers and alternatives) or the relational space (i.e., efforts to establish a positive group climate and to ensure effective and efficient collaboration) of collaboration (Barron, 2003; Slof, Erkens, Kirschner, Jaspers, \& Janssen, 2010), may be caused by a lack of group awareness (Janssen, Erkens, \& Kanselaar, 2007; Janssen, Erkens, Kanselaar, \& Jaspers, 2007; Jermann \& Dillenbourg, 2008). Recently, researchers have begun to examine how group awareness tools can be used to enhance group awareness and to study whether group awareness tools affect collaborative learning and group performance (Dourish \& Bellotti, 1992). The aim of this article is to examine how use of a group awareness tool affects the collaborative learning process and group performance. 
Rafael: What do you think of the Debate now?

Casey: Fine.

Rafael: And what did you do Casey?

Rafael: Nothing was added to the Debate...?

Rafael: What are you doing now in the Debate, Case? Don't put anything

in there cos you'll mess up the order.

Casey: Oops. Too late!

Casey: I've added source 3 to propaganda as a new argument. By accident!!

Rafael: I see. Grrrrr :-|

Rafael: Do you know what Lara is doing?

Casey: She's supposed to be working on the Martyrs position...

Rafael: I get the feeling she's letting us do most of the work.

Casey: So do I!

The chat fragment above comes from two male secondary education students working in a CSCL environment. They are members of a 3-person group, and they are currently working on the creation of a representation of a historical debate in an argumentative diagram called the Debate-tool. This fragment highlights two of the most common problems that group members encounter during online collaboration. Rafael is uncertain about what Casey is doing in the Debate-tool. He warns Casey about messing up the order in the tool, but he is too late. This is a sign of coordination problems with respect to the content space of collaboration. Additionally, they wonder about their other group member, Lara. They have no idea what she is doing, if she is even online, and whether she is doing what she is supposed to be doing. On top of that, they are afraid she is letting them do the lion's share of the work, but they do not know that for sure. This is an indication of coordination problems in the relational space. In sum, this fragment illustrates Rafael and Casey lack awareness information (CSCW, Schmidt, 2002).

The issue of awareness has received considerable attention in the area of computersupported cooperative work (Dourish \& Bellotti, 1992). This has led to a multitude of definitions of awareness and to the identification of a large number of different forms of awareness, such as passive awareness (Gutwin \& Greenberg, 2002), workspace awareness 
(Bødker \& Christiansen, 2006), social awareness (Mendoza-Chapa, Romero-Salcedo, \& Oktaba, 2000), conversational awareness (Kreijns \& Kirschner, 2001), history awareness (Engelmann, Dehler, Bodemer, \& Buder, 2009), knowledge awareness (Buder \& Bodemer, 2008), and group awareness (Gutwin, Stark, \& Greenberg, 1995). Although there are differences between these forms of awareness and their definitions, their main commonality is their focus on information, or rather, the lack thereof in CSCL environments. In CSCL environments, it is often difficult to obtain information about what the other is doing, whether he/she is available for communication and interaction, what the others know about the task at hand, what group members will do next, and so on (Romero-Salcedo et al., 2004). In this study we focus on group awareness, which can be defined as knowledge about the social and collaborative environment the person is working in (e.g., knowledge about the activities, presence or participation of group members; see Buder \& Bodermer, 2008).

If group awareness is a problem of perception and information (Gutwin \& Greenberg, 2004), why would this be problematic for group members working in a CSCL environment? Consider the chat-fragment above. Because Rafael and Casey lack information about their group members' activities, their collaboration is far from smooth. Note for instance Rafael's irritation after Casey’s mistake. Group awareness information can reduce group members’ efforts to coordinate their actions, can increase their efficiency, and reduce the chance of errors (Salomon \& Globerson, 1989).

During collaboration, group members have to engage in different types of activities. These activities often have to do with the execution of the task, while others have to with the coordination and regulation of the task. But group members also need to regulate and coordinate the social aspect of collaboration. For instance, they need to coordinate their collaboration: Who is available for discussion and communication? Who needs help? Is the collaboration going fine or should changes be made? This means that group members need 
awareness information about the relational space as well as information about the content space of collaboration. A common problem in collaboration is for example, the free rider effect: one student lets the other group members do most of the work (Buder \& Bodemer, 2008). This is obviously not in the best interest of the group and therefore needs to be avoided. But it is often very difficult to determine whether free riding behavior is occurring. Rafael and Casey think that Lara might be taking a free ride, but without the proper information they cannot be certain. Thus, while working in a CSCL environment, group members not only require awareness information about the content space, but also about the relational space. In sum, CSCL environments should incorporate tools or mechanisms that offer students group awareness information to facilitate coordination and regulation of activities in both spaces. Such tools are called group awareness tools (Kirschner, Paas, \& Kirschner, 2009; Van Bruggen, Kirschner, \& Jochems, 2002).

\section{Using Group Awareness Tools to Increase Group Awareness}

Collaborating in CSCL environments is a complex endeavor. Group members have to carry out many different activities, while keeping track of the overwhelming amount of information that is available in the environment (e.g., the chat history detailing all the decisions that were made by the group or the version history of shared documents that are being written). The collection and interpretation of such information is a cognitively demanding task. From the perspective of cognitive load theory (Ware, 2005, p. 29), collaboration in these environments generates high levels of intrinsic and extraneous cognitive load (Keller \& Tergan, 2005; Sweller \& Chandler, 1994), for example due to the necessity to keep track of group members' actions and the progress of the task as well as the need to communicate with group members to ensure optimal inter-individual coordination. 
Group awareness tools can assist students in collecting the required information to collaborate effectively in CSCL environments. One approach to develop such tools is to visualize information that is important for the development of group awareness (Ainsworth, 2006). Visualizations can make it easier to collect and interpret this information, because "it is possible to have a far more complex concept structure represented externally in a visual display than can be held in visual and verbal working memories” (Erkens et al., 2005). Visualizations can display large amounts of information and can facilitate its interpretation. They can therefore decrease the cognitive demands placed on individuals (Savicki, Kelley, \& Ammon, 2002). Visualizations for example, facilitate computational offloading (Lipponen, Rahikainen, Lallimo, \& Hakkarainen, 2003) since team members need to invest less effort to collect and interpret the information they need to collaborate successfully in a CSCL environment. On the other hand, adding visualizations to a CSCL environment to enhance group awareness can also increase cognitive load for students, because they have to pay attention to the visualization and have to interpret the information displayed by the visualization.

In this study, students used a group awareness tool called the Participation-tool (PT, see Figure 1) while they were collaborating in a CSCL environment called Virtual Collaborative Research Institute (VCRI, see Figure 2). VCRI is a groupware application designed to facilitate and support collaboration on complex inquiry tasks and research projects (Cohen, 1994). VCRI consists of several tools which are shared by the group members (i.e., students can modify their contents and these modifications are visible to the other group members). The Chat-tool shown in the upper left window is used for synchronous communication between group members. The chat history is stored automatically and can be re-read at any time. Using the Cowriter shown in the upper right window, students can simultaneously formulate their answers or write their research reports. 
The PT visualizes how much each group member contributes to his or her group’s online collaboration and thus focuses on a specific aspect of group awareness, awareness of participation. Research has shown that during online collaboration unequal participation sometimes may occur in some groups (Webb, 1995). Moreover, in some studies researchers have noted low participation rates of all group members (Kirschner, Beers, Boshuizen, \& Gijselaers, 2008). This may be a cause for concern, because student participation during collaboration affects group performance and student achievement (Butler \& Winne, 1995). When students participate actively during online collaboration and participation is divided equally among group members, every group member has the opportunity to contribute to the problem solving process, to participate in knowledge construction, to give or request explanations, and to use and refine his or her skills (2008). The PT was designed to enhance group awareness - more specifically awareness of participation - by giving group members awareness information about their participation levels.

In the PT, each group member is represented by a sphere. While group members are collaborating, the visualization displayed in the PT is continually updated, allowing group members to compare their own participation with the participation of the other group members. The distance of a sphere to the group center indicates the number of messages sent by the represented student compared to the other group members. When a sphere is located closer to the center of the group, the student has sent relatively more messages than a student who is located farther from the center. This aspect of the PT therefore focuses on student participation in the relational space. In contrast, the size of the sphere indicates the amount of keystrokes typed in the other tools of the VCRI (e.g., the number of keystrokes in the Cowriter while writing the group product) compared to the other group members. If a sphere is smaller, the student has typed less keystrokes than a student whose sphere is larger. This 
aspect of the PT gives awareness information about students' participation in the content space (e.g., how much the student has contributed to the group product).

The PT is not a shared but an individual tool and can be opened and examined by students at any time. The visualization can be rotated using the mouse, to examine the visualization from a different perspective. After opening the PT, students can drag its window to any place on their screen and can adjust the size of the window. It should be noted that this means that students can also obstruct their view of the other tools with the PT and that they can obstruct their view of the PT with one of the other tools. The PT can display students' cumulative participation rates (i.e., total number of messages sent at any moment), but can also display a moving average. The moving average displays students’ participation rates during the past 20 minutes. This was included because when students have sent many messages and have typed many keystrokes, sending one long message or typing a considerable text section in the Cowriter will not greatly affect the cumulative display. In a period of 20 minutes however, the total number of messages and keystrokes is limited, which means that active participation has more impact on the visualization (e.g., the size of the sphere will increase more dramatically). Finally, it is important to note that students are not forced or coerced to use the PT (Zumbach, Hillers, \& Reimann, 2004; Zumbach \& Reimann, 2003). In order words, the tool is available and students can use it whenever they want, but students do not have to open the tool and they can also choose to ignore or close it whenever they want.

Insert Figure 1 about here

Insert Figure 2 about here 


\section{Effects of Using Group Awareness Tools on Online Collaboration}

The current study aims to explore the relationship between the use of a group awareness tool and the online collaborative process. Group awareness tools can be used to generate external feedback (Gutwin \& Greenberg, 2004; Kirschner, Strijbos, Kreijns, \& Beers, 2004). This feedback provides group members with information they can use to monitor the progress of their collaboration. It allows them to determine whether selected strategies are working as expected, and whether group performance and products are up to standard.

Jermann and Dillenbourg (2008) for example, developed a visualization in one of their studies which gives feedback about dyad members’ activities in a computer-supported simulation environment. Dyads collaborate on a task which requires them to tune the lights of a traffic simulation so as to minimize waiting time for car drivers. This requires them to 'talk' (visualized by the number of chat messages sent) and to 'tune' the traffic lights (visualized by the number of times the traffic lights were tuned in the simulation). The visualization shows the amount of talking and tuning done by the group members using bar charts. This allows group members to compare themselves to one another. Jermann and Dillenbourg (2008) could not however, establish an effect of their awareness tool on participation and equality of participation during online collaboration, or an effect on group performance.

Another example of how group awareness tools can be embedded in CSCL environments to give feedback to group members comes from the work of Zumbach and colleagues (2007). The environment tracks group members' activity and feeds this back to the users in a pie chart. In sum, these group awareness tools provide group members with feedback on how well they are collaborating (i.e., are group members participating equally in 
the collaborative process?). In their studies Zumbach et al. showed that their group awareness tool positively affected students’ learning process, group performance, and motivation.

Group awareness tools can enhance the awareness information CSCL environments offer to group members and could thus raise students' group awareness (Shepperd, 1993). The group awareness tools developed by Jermann and Dillenbourg (2004) and Zumbach and colleagues (Michinov \& Primois, 2005) provide information about who the most active participants of the group are. This information may enhance students' awareness of group processes, and more specifically, of group member participation (i.e., the group awareness tools affect awareness of participation). This enhanced group awareness may in turn help students to decide whether it is necessary to change their collaborative behavior. In a previous study for example, Janssen, Erkens, Kanselaar et al. (2007) found that students who used the PT reported higher awareness about free riding behavior by group members, compared to students who did not use the PT. Thus, the following hypothesis may be formulated:

(H1) Use of the PT will increase students' awareness of participation.

Group awareness tools such as the PT may also affect students’ motivation to participate during online collaboration. The contribution of each group member to the online collaboration is made identifiable when participation is visualized. This identifiability may motivate students to put effort into the collaboration and the task. For example, the PT can motivate students to participate more, because they are unable to hide in the crowd and they may be evaluated negatively when they are seen as free riders (2008). Zumbach et al. (Clarebout \& Elen, 2006; Jiang, Elen, \& Clarebout, 2009)In addition, group awareness tools such as the PT create opportunities for social comparison. This means that by comparing 
themselves to other group members, students may be motivated to set higher standards for themselves and to try to increase their participation (2005).

Michinov and Primois (2005) for example, stimulated social comparison processes by providing students with measures of their group members' participation in a table that could be read by all group members. They found that their group awareness tool positively affected group member participation. A similar effect was found by Janssen, Erkens, Kanselaar et al. (2007). Jermann and Dillenbourg (2008) however, found no effect of their group awareness tool on group member participation.

Because students can usually decide for themselves whether they use group awareness tools or not (i.e., the learning environment does not advise students to use the tool, nor is its use coerced), variations in use of the tools will therefore occur (e.g., because students do not perceive the value of the information displayed or do not understand the representation). This means that the effect of group awareness tools on online collaboration will - at least partially - depend on group members' ability to make adequate choices about the added value of the tool for their collaboration (cf., Savicki et al., 2002).

This may also explain why group awareness tools were found to affect group member participation in the studies conducted by Michinov and Primois (2007) and Janssen, Erkens, Kanselaar et al. (2008), but not in Jermann and Dillenbourg's (Barron, 2003; Slof et al., 2010) study. It may be possible that students in the studies by Michinov and Primois and Janssen, Erkens, Kanselaar et al. used the group awareness tool more frequently or more appropriately than students in the study by Jermann and Dillenbourg. Investigating how use of group awareness tools affects group member participation may therefore enhance our understanding of the effects of group awareness tools. Furthermore, group awareness has been identified as an important mechanism in online collaboration: by increasing group awareness, the collaborative process may become more effective and efficient (i.e., group 
awareness acts as a mediating variable when investigating the effects of group awareness tools). However, research has not yet addressed whether group awareness actually plays this mediating role in explaining the effect of group awareness tools on online collaboration. We will therefore examine the following two hypotheses:

(H2a) Use of the PT will increase students’ participation during online collaboration and

(H2b) this effect will be (partially) mediated by group awareness.

During online collaboration, students sometimes engage in social loafing or free riding behavior (McGrath, 1991). Because the PT is expected to stimulate social evaluation and social comparison among group members, the PT may not only stimulate group member participation, but may also stimulate equality of participation among group members. Because students can be evaluated by their group members based on the information provided by the PT, they may do their best to try to participate as much as their group members. The group awareness tools developed by Janssen, Erkens, Kanselaar et al. (Kreijns, Kirschner, \& Jochems, 2003) and Jermann and Dillenbourg (Manlove, Lazonder, \& De Jong, 2006) however, did not affect equality of participation. As noted before, this may also be due to differences in students' use of the group awareness tool and subsequent differences in students' group awareness. The following two hypotheses will therefore be investigated:

(H3a) Use of the PT will lead to more equality of participation during online collaboration and

(H3b) this effect will be (partially) mediated by group awareness. 
When students collaborate on complex tasks in CSCL environments, they have to attend to two different interaction spaces (Phielix, Prins, \& Kirschner, 2010). In the content space of collaboration, they have to exchange their ideas and opinions, ask questions, formulate and revise answers, and work towards a group product (Fischer, Bruhn, Gräsel, \& Mandl, 2002; Teasley \& Roschelle, 1993). In the relational space, group members have to perform social and communicative activities that foster group well-being (2007). Furthermore, the problem-solving and interaction processes in both spaces have to be coordinated and regulated. Metacognitive activities that regulate activities in the content space (e.g., making plans, monitoring task progress, and evaluating plans or ideas) are considered important to successful performance during collaboration (Bonito, 2000; Cohen, 1994). Moreover, collaboration also requires coordination or regulation of activities in the relational space (cf., Yager, Johnson, Johnson, \& Snider, 1986). During collaboration, group members have to discuss collaboration strategies, monitor collaboration processes, and evaluate and reflect on the manner in which they collaborated (Kirschner et al., 2009).

The awareness information offered by the PT may trigger coordination and regulation of activities in the relational space, because it raises group members' awareness. Coordination and regulation may furthermore be facilitated because group awareness tools can mediate discussion as is the case when they help group members externalize and articulate their thoughts about collaboration processes by providing them with appropriate information and concepts (cf., Jiang et al., 2009). After examining the group awareness tool developed by Jermann and Dillenbourg (2008) for example, a group member may feel that his partner is free riding, which may stimulate him or her to discuss this by referring to the group awareness tool.

In a previous study using the PT, Janssen, Erkens, Kanselaar et al. (2007) examined the impact of the PT on coordination and regulation of activities in the relational space. They 
found that, compared to a control group that did not use the PT, students that used the PT discussed more about the coordination and regulation of their collaboration. This can be seen as evidence that the group awareness tool affected the occurrence of coordination and regulation of the relational space. Thus, the following two hypotheses will be examined:

(H4a) Use of the PT will lead to more coordination and regulation of activities in the relational space and

(H4b) this effect will be (partially) mediated by group awareness.

Our last hypotheses address the effect of using the PT on group performance (i.e., the quality of the group products created by the group members). In light of the above, it may be assumed that use of the PT will positively affect group performance. For example, when groups use the PT more intensively, group member participation will be higher and participation will be divided more equally among group members. This will help these groups to perform better (e.g., Adrianson, 2001). Furthermore, these groups will also devote more time and effort to coordinating and regulating activities in the relational space. When group members engage in these activities their collaboration will likely improve, resulting in increased group performance (e.g., Savicki et al., 2002; Straus, 1997). This study will therefore address the following hypotheses:

(H5a) Use of the PT will lead to higher group performance and (H5b) this effect will be mediated by group awareness. 


\section{METHOD}

\section{Participants}

Participants were eleventh-grade students from five history classes in two secondary education schools in the Netherlands. Both schools were comparable in terms of socialeconomical status of the attending students. The total sample consisted of 107 students (49 male, 58 female) working in 35 three-person and two four-person groups (22 groups in the first school, 13 groups in the second school). Mean age of the students was 16.21 years $(S D=0.63, \operatorname{Min}=15, \operatorname{Max}=18)$. Students were assigned randomly to a group, group composition was therefore heterogeneous with respect to variables such as prior knowledge and gender.

Materials

\section{Collaborative Learning Environment}

The participating students collaborated in a CSCL-environment called Virtual Collaborative Research Institute (VCRI, see Figure 2). Besides the Chat-tool, Cowriter, and Participation-tool mentioned in the Introduction, the VCRI contains several other tools. For example, to complete the inquiry group project, students have to read several information sources containing important information. These information sources are included in the VCRI and are listed in the Sources-tool (bottom left window of Figure 2). An opened information source is visible in the bottom right window. Students can read the information displayed here from their screens and use it for their inquiry task or research project.

\section{Inquiry Group Task}

Students collaborated on a historical inquiry task. The subject of the task was "The first four centuries of Christianity” and consisted of three parts. The task can be characterized as an open-ended task without a standard procedure and a single correct answer. For the first part of the inquiry task, the groups had to answer four different questions pertaining to the 
first four centuries of Christianity. To answer these questions, 12 different sources were available to the students. These sources were, for example, fragments from the New Testament, and historical texts from the Roman era. Additionally, students could search the Internet or their textbooks for more information. To complete the second part of the task, the groups had to study 40 different sources about the subject. These sources needed to be categorized into up to five different categories. Furthermore, group members were instructed to construct a diagram of their categorization using the Diagrammer. Finally, students had to write a short text, explaining how and why they categorized the different sources. For the final part of the inquiry task, group members had to collaboratively write an essay of at least 1200 words. The essay had to explain why and how Christianity developed from a small 'cult' into the main religion of the Roman Empire. The task was complex and group members had to share and divide the available information sources. Active participation and cooperation of all group members was therefore necessary to successfully complete the inquiry task (Howell-Richardson \& Mellar, 1996). Students collaborated on the task for eight 50-minute lessons.

Measures

Use of the Participation-tool

To analyze how students used the PT during their online collaboration, all user actions in the VCRI-environment were logged and stored. From the log files two scores were calculated to reflect students' use of the PT (Erkens \& Janssen, 2008; Erkens et al., 2005). First, the number of times a student used the PT was calculated (e.g., opening and closing the tool, changing the view from cumulative to moving average, etc.). This reflects the intensity with which the PT was used by the students. Additionally, the amount of time the PT was displayed on the student's screen was calculated. For example, when a student opened or 
maximized the PT and closed or minimized the tool five minutes later, 5 minutes were added to the total time. This provides a measure for the overall duration of PT use.

\section{Group Awareness}

Students' group awareness of the participation of their group members during the online collaboration (i.e., awareness of participation) was measured using a 4-item questionnaire developed by Janssen et al. (Erkens, 2005). A sample item from this scale is: "I knew how much my group members contributed to the collaboration”. Students provided answers to the statements on a 5-point scale (ranging from $1=$ completely disagree to $5=$ completely agree). Cronbach’s alpha was .72.

\section{Student Participation during Online Collaboration}

To examine the impact of the PT on students' participation levels in the chat discussions, we had to decide on an appropriate measure. Two obvious choices are the number of chat messages sent (see Erkens \& Janssen, 2008) or the number of words written during the chat conversations (Janssen, Erkens, \& Kanselaar, 2007; Janssen, Erkens, Kanselaar et al., 2007). These measures do not however, reflect the nature of synchronous computer-mediated communication very well (Erkens et al., 2005). During chat conversations some users only send one proposition per message, while other users type multiple sentences which combine several propositions. The chat messages sent by the students were therefore segmented into dialogue acts (Manlove et al., 2006). Dialogue acts signal the communicative function of a message to receivers (e.g., responding, informing, argumentation). One dialogue act corresponds to one proposition.

Segmentation of the chat messages was done using the Multiple Episode Protocol Analysis (MEPA) program (Webb \& Palincsar, 1996). Messages were segmented using a segmentation filter (Kenny, Kashy, \& Cook, 2006; Kenny, Mannetti, Pierro, Livi, \& Kashy, 2002), which is a program specified and used in MEPA for automatic rule based data 
manipulation. Punctuation marks (e.g., full stop, question mark, comma) and phrases connected through a conjunction (e.g., “and”, "but”, "if”) were used to segment chat messages into dialogue acts. For each student the total number of dialogue acts was calculated. This measure can be used as an indication for group members' participation in the chat discussions.

Furthermore, we extracted for each group member the number of keystrokes he or she typed in the Cowriter. We considered this measure an indication of students' participation during the collaborative writing process.

\section{Equality of Participation}

The Gini coefficient was used as a measure of equality of participation (research question 4). This is a group level measure calculated for each of the 35 groups. For each group, the deviation of its group members from equal participation is summed. This sum is then divided by the maximum possible deviation from this value (Cress, 2008). The Gini coefficient can range from 0 (all students sent the same number of dialogue acts) to 1 (one student sent all dialogue acts and his/her group members sent none).

\section{Coding of Online Discussion}

To examine whether use of the PT affects group members’ discussion of the collaborative process (e.g., formulating and choosing collaborative strategies or monitoring the group process) a coding scheme was used to analyze the chat messages sent by the students. This coding scheme was developed in earlier studies (Baron \& Kenny, 1986). In total, the coding scheme consists of four dimensions. The first dimension concerns activities carried out in the content space of collaboration, such as proposing solutions, asking taskrelated questions, and exchanging relevant information. The second dimension is used for activities that address the relational space of collaboration. These activities include negotiation of meaning and making positive comments to ensure a sound social space. The 
third dimension addresses activities that coordinate and regulate activities in the content space, such as planning the problem-solving process and monitoring task progression. The final dimension is reserved for activities that coordinate and regulate activities in the relational space, for example when group members evaluate their collaboration. In total, the coding scheme consists of 19 codes. For this article we focused on the effect of using the PT on students' attempts to coordinate and regulate activities in the relational space. By giving feedback about group members' level of participation during the collaboration, the PT enhances group members' awareness. It is expected that group members will use this information to discuss their collaboration with each other and to coordinate and regulate their activities in the relational space (see hypotheses $4 \mathrm{a}$ and $4 \mathrm{~b}$ ). We will therefore only describe the last dimension of our coding scheme in detail. For more information about the other dimensions, the reader is referred to the above mentioned publications.

When students collaborate on an inquiry task, they have to perform activities in the content space and in the relational space. On the other hand, successful coordination also requires considerable coordination and regulation of these activities (MacKinnon, Fairchild, \& Fritz, 2007). In this study, we focus on how group members coordinate and regulate activities in the relational space of collaboration (Baron \& Kenny, 1986; MacKinnon et al., 2007). During the regulation of activities in the relational space, students engage in group processing, which means they discuss how well their group is functioning and how group processes may be improved (Shrout \& Bolger, 2002). The coding scheme used in this study uses four different codes to identify coordination and regulation of activities in the relational space. Planning involves discussion of collaborative strategies, such as helping each other or proposals to work together on certain tasks. Second, monitoring refers to exchange of information that group members use to monitor group processes (e.g., group members discuss the progress of collaborative tasks). Finally, positive and negative evaluations refer to 
appraisal and evaluation of group processes and collaboration (e.g., a student remarks he/she is happy with the way the group is working together).

In our analyses, we calculated for each group member the total number of statements that coordinate and regulate activities in the relational space (i.e., the sum of planning, monitoring, and evaluating). The objectivity of the coding scheme was assessed by two independent coders, using Cohen’s kappa. A satisfactory Kappa of .90 was found.

\section{Group Performance}

To measure the effect of using the PT on group performance, we assessed the quality of the group products handed in by the groups. For each of the three subtasks of the inquiry task we assessed both the conceptual content and quality of argumentation (e.g., use of relevant historical concepts, quality of reasoning and argumentation) and the quality of the presentation of the answers (e.g., structure of the written text, correctness of language used) using an assessment form. In total, the form consisted of 20 items rated on a 3-point scale ( 0 = low quality, 2 = high quality). Interrater reliability analyses using two independent coders indicate the assessment procedure was sufficiently objective (Cohen’s Kappa ranged from .72 - .90). In our analyses we calculated mean overall performance scores in such a way that a group that was given the maximum amount of points for all of the 20 items (40) received an overall mean score of 1 , while a group that was given the minimum amount of points (0) received an overall mean score of 0.

\section{Procedure}

Students worked on separate computers in a computer lab during the eight lessons. Before the start of the first lesson, students were instructed about the inquiry task and the VCRI-environment. During this introduction several important tools of the environment were explained to the students, including the PT. Our explanation of the PT focused on how the tool should be used, how the information visualized should be interpreted. The explanation 
why the tool is beneficial was kept to a minimum so as not to influence students' use of the PT too much.

During the lessons, teachers answered task-related questions, while an experimenter answered technical questions about the environment. The teachers were able to monitor the online discussions of their students when they logged into the VCRI environment. Teachers could also send messages in order to answer students' questions, or to warn students in case of misbehavior. Furthermore, teachers had access to the texts students are writing in the Cowriter. This way, teachers could monitor the progress of their groups. Students were allowed to work on the inquiry task during free periods in their time schedule. After eight lessons students handed in their final version of the task for grading by their teacher.

Insert Figure 3 about here

RESULTS

Insert Table 1 about here

Use of the Participation-tool

As can be seen in Table 1, students manipulated the PT (e.g., opening, closing or rotating the view) on average 77.36 times $(S D=38.92)$ and displayed the PT on their screens for 66.82 minutes $(S D=43.36)$. Because the average time a student was online in the VCRI environment was 405.60 minutes $(S D=104.36)$, this means most students displayed the PT on their screens for a considerable amount of time (16\%) and manipulated the PT on a regular basis (about once every 5 minutes). Unsurprisingly, intensity of PT use and display time of the PT correlated significantly, $r=.23, p=.02$. 
We also examined whether the intensity and duration with which students manipulated the PT changed over the course of the experiment. Figure 3 shows that in the first week of the experiment, students used the PT most intensively and for the longest duration. After the first week, a significant drop in both intensity and duration can be seen. Half way through the duration of the collaborative project (week 4), intensity and duration of PT use are at their lowest, but then rise again in week 5 and 6. Finally, intensity and duration decrease again in the last two weeks of the collaboration. It seems that during the beginning of the study, the students were learning to manipulate the PT through a trial and error strategy, which explains the relatively high intensity and duration scores in the first week. After the first week, students use the tool less often in weeks 2, 3 and 4.

Insert Table 2 about here

Insert Table 3 about here

\section{Group Awareness}

From Table 1 it becomes clear that on average students reported moderate levels of awareness of their group members' levels of participation $(M=3.21, S D=0.67)$. When investigating the effect of use of the PT on awareness of participation, the problem of nonindependence had to be taken into account (Kenny et al., 2006). Because students worked in groups, they influenced each other. This violates the assumption of nonindependence of observations of individuals, making the results of traditional analytical techniques such as regression or correlation analysis unreliable (2009). Multilevel analysis (MLA) however, can cope with nonindependence and is therefore a more appropriate technique. 
Table 2 shows the results of a MLA investigating the effects of intensity of PT use on awareness of participation. As can be seen, intensity of PT use did not have a significant effect on awareness of participation. In contrast, Table 3 shows that duration of PT use significantly affected awareness of participation: students who displayed the PT on their screen longer reported higher awareness of their group members’ levels of participation. Hypothesis 1 is therefore partially supported.

Insert Table 4 about here

Insert Table 5 about here

\section{Student Participation during Online Collaboration}

On average, students typed a total of $294.92(S D=184.46)$ dialogue acts in VCRI's Chat-tool during their collaboration (see Table 1). Tables 4 and 5 show the results of the analyses of the effect of PT use on student participation during chat discussions (number of dialogue acts sent). No effect of intensity of PT use on student participation was found (see Table 4). However, a significantly positive effect of overall duration of PT use on student participation during chat discussions was found (see Table 5). The positive sign of $\beta_{1}$ indicates that students who displayed the PT on their screen for a longer period of time, participated more during the chat discussions. Hypothesis 2a is therefore partially supported.

Insert Table 6 about here 
Insert Table 7 about here

Table 1 also shows students' participation in the Cowriter. On average students' typed 6816.50 keystrokes in the Cowriter $(S D=1938.87)$. The MLA displayed in Table 6 shows that intensity of PT did not significantly affect student participation in the Cowriter. Overall duration of PT use was, in contrast, found to affect student participation in the Cowriter, as can be seen in Table 7. Students who used the PT for a longer period of time, contributed more keystrokes to the texts written in the Cowriter. These findings again partly support Hypothesis 2a.

Insert Figure 4 about here

To investigate whether the effect of using the PT on student participation in the chat discussions is mediated by awareness of participation (Hypothesis $2 \mathrm{~b}$ ), a mediation analysis was conducted (Molinari, Sangin, Dillenbourg, \& Nussli, 2009; Sangin, Molinari, Nüssli, \& Dillenbourg, 2008; Van Gog, Kester, Nievelstein, Giesbers, \& Paas, 2009). Baron and Kenny recommend a three step procedure to determine whether mediation exists. All three steps must be met for complete mediation to exist. The first step is met if the initial predictor variable (e.g., intensity of PT use or overall duration of PT use, denoted $X$ in Figure 4) correlates significantly with the mediator (e.g., awareness of participation which is denoted $M$ in Figure 4). If this is the case, path $a$ in Figure 4 is significant. If the presumed mediator significantly predicts the dependent variable (e.g., student participation in chat discussions, denoted $Y$ in Figure 4) while controlling for the initial predictor variable (path $b$ in Figure 4), the second step is met. Finally, the third step is met when the effect of the initial predictor variable on the dependent variable, while controlling for the mediator, is zero (path $c^{\prime}$ ). This 
means the effect of $X$ on $Y$ is completely mediated by $M$. However, if step 3 is not met, it can be tested whether partial mediation exists, using a Sobel test (Gutwin \& Greenberg, 2004; Kirschner et al., 2004).

The results displayed in Table 1 indicate that step 1 is not met for intensity of PT use (path $a$ is not significant), while this step is met for overall duration of PT use (path $a$ is significant), $\beta=.296, p=.002, r^{2}=.089$. We therefore did not conduct steps two and three for intensity of PT use. Next, our analyses show that for overall duration of PT use, step 2 has been passed. The results showed a significantly positive relationship between awareness of participation and student participation in the chat discussions, $\beta=.245, p=.010, r^{2}=.060$. Path $b$ is therefore significant. Step 3 was not passed however, because the effect of overall duration of PT use on student participation controlling for awareness of participation was still significant, $\beta=.282, p=.003, r^{2}=.081$. The Sobel test however, showed that the indirect effect was significant, $Z=2.043, p=.041$, meaning that awareness of participation can be considered a partial mediator for student participation in the chat discussions (e.g., asking for elaborated help and giving elaborated explanations, see Webb, Nemer, \& Zuniga, 2002). The percentage of the total effect of overall duration of PT use on student participation that is mediated by awareness of participation is $20.73 \%$ (e.g., prior knowledge, achievement motivation, see Dillenbourg, Baker, Blaye, \& O'Malley, 1996). Hypothesis 2b is therefore partially supported.

Mediation analyses were also performed to investigate whether awareness of participation mediated the effect of intensity of PT use and overall duration of PT use on student participation in the Cowriter. Because step 1 is similar to step 1 for student participation in the chat discussion, path $a$ is not significant for intensity of PT use but it is significant for duration of PT use. Next, awareness of participation when controlling for overall duration of PT use significantly predicted student participation in the Cowriter, 
$\beta=.248, p=.010, r^{2}=.062$. Path $b$ is therefore significant, and step 2 has been met for duration of PT use. Finally, our analyses showed that overall duration of PT use when controlling for awareness of participation significantly predicted number of keystrokes typed in the Cowriter, $\beta=.250, p=.009, r^{2}=.064$. This means path $c^{\prime}$ is significant and step 3 has not been passed. The Sobel test however, showed that the indirect effect of awareness of participation was significant, $Z=2.028, p=.043$, meaning that awareness of participation can be considered a partial mediator for student participation in the Cowriter. The percentage of the total effect of overall duration of PT use on student participation in the Cowriter that is mediated by awareness of participation is $22.69 \%$. These findings also provide partial support for Hypothesis 2b.

\section{Equality of Participation}

Over the 35 groups in our study, a mean Gini coefficient of $.15(S D=.07)$ was found (see Table 1). This indicates that in most groups students contributed roughly equally to the online collaboration. Because equality of participation is a group level variable, it was necessary to aggregate the two PT-variables to the level of the group. These measures then indicate the intensity with which the group used the PT and the overall duration of PT use by the group. Because all variables of interest are now measured at the level of the group and nonindependence is therefore no longer a problem (e.g., Buder \& Bodemer, 2008; Gutwin \& Greenberg, 2004; Kirschner et al., 2004), these aggregated variables were subsequently correlated with our equality of participation measure. As can be seen in Table 1, intensity of PT use was not significantly correlated with equality of participation, $r=-.02, p=.92$. On the other hand, a significant correlation was found between overall duration of PT use by the group and equality of participation, $r=-.36, p=.03$. Thus, in groups that had the PT on their screens for a longer period of time, participation between group members was more equal. Hypothesis 3a is therefore partially supported. 
To test Hypotheses 3b, mediation analyses were also conducted. Intensity of PT use did not correlate with awareness of participation (see Table 1), therefore step 1 has not been passed. We therefore did not examine steps 2 and 3 for this variable. In contrast, overall duration of PT use correlated significantly with awareness of participation. For this variable, path $a$ was therefore significant. Furthermore, the results also show that path $b$ is significant: awareness of participation significantly predicts equality of participation while controlling for overall duration of PT use, $\beta=.298, p=.043, r^{2}=.089$. Step 2 has been passed. Step 3 was not passed however, because the effect of overall duration of PT use on equality of participation controlling for awareness of participation was still significant, $\beta=-.783, p=$ $.000, r^{2}=.487$. The Sobel test showed a nonsignificant indirect effect of the mediator variable, $Z=1.709, p=.087$, meaning awareness of participation does not mediate the effect of overall duration of PT use on equality of participation. Hypothesis 3b is therefore rejected.

Insert Table 8 about here

Insert Table 9 about here

\section{Coordination and Regulation of Relational Space}

On average, 19.52 of the dialogue acts sent by the students were used for coordination and regulation of the relational space ( $S D=15.44$, see Table 1$)$. This is equal to about $7 \%$ of the total number of dialogue acts. Tables 8 and 9 show the results of MLA investigating the effects of intensity of PT use and overall duration of PT use on students' use of strategies that coordinate and regulate activities in the relational space. As can be seen, intensity did not predict coordination and regulation of the relational space. On the other hand, duration of PT 
use significantly predicted coordination and regulation of the relational space. Hypothesis 4a is therefore partially supported.

Mediation analyses were not performed for the effect of intensity of PT use on activities that coordinate and regulate the relational space, because path $a$ was not significant and step 1 has not been met. Concerning overall duration of PT use, path $a$ is similar to path $a$ for the previous mediation analyses for this variable. Step 1 has therefore been met. Step 2 was not met however, because awareness of participation did not predict coordination and regulation of the relational space, $\beta=.168, p=.090, r^{2}=.028$. Unsurprisingly, the final step showed that duration of PT use was a significant predictor for coordination and regulation of the relational space when controlling for awareness of participation, $\beta=.204, p=.040$, $r^{2}=.040$. Moreover, the Sobel test showed a nonsignificant indirect effect of the mediator variable awareness of participation, $Z=1.514, p=.130$. Step 3 has not been passed and hypothesis $4 \mathrm{~b}$ is therefore rejected.

\section{Group Performance}

Comparable to equality of participation, group performance is also a group level measure. This measure was again correlated with the aggregated measures for intensity of PT use and duration of PT use. The 35 groups participating in this study performed a little bit above average $(M=.58, S D=.10)$. Intensity of PT use and duration of PT use did not correlate with group performance, $r=-.04, p=.81$, and $r=.27, p=.12$. Hypothesis 5 a is thus rejected.

Like the previous mediation analyses, step 1 involved investigating the effect of intensity of PT use and duration of PT use on awareness of participation (path $a$ ). Thus only in the latter case path $a$ was significant. Furthermore, path $b$ was not significant because awareness of participation did not significantly predict group performance when controlling for duration of PT use, $\beta=.287, p=.129, r^{2}=.071$. The final step showed that duration of 
PT use did not predict group performance when controlling for awareness of participation, $\beta=.140, p=.454, r^{2}=.018$. Moreover, the Sobel test showed a nonsignificant indirect effect of the mediator variable awareness of participation, $Z=1.376, p=.169$. Hypothesis $5 \mathrm{~b}$ is therefore also rejected.

\section{CONCLUSION AND DISCUSSION}

The present study examined the effect of using the Participation-tool (PT) on online collaboration. Furthermore, we examined whether the effect of using the PT on online collaboration is mediated by awareness of participation. To answer these questions, we determined the intensity with which secondary education students used the PT and how they used the PT. Our results show that students used the PT quite intensively, although large variations existed between individual students.

Contrary to our expectations, only one of the two variables we used to measure use of the PT affected the online collaborative process. The first measure was calculated by adding up all the mouse clicks in the PT of a student (e.g., clicking on a button to zoom in or out) and reflected intensity of PT use. The second measure was calculated by adding up the total amount of time the PT was displayed on the student's screen and reflected overall duration of PT use. Only the latter measure significantly predicted variables related to the online collaboration. This finding mirrors a results reported by Jiang et al. (Strijbos, Martens, \& Jochems, 2004), who also found that frequency of tool use did not affect performance in an computer-based learning environment, while time spent using the tool did affect performance. An important question is therefore: Why does the former measure not affect online collaboration, while the latter does? It might be argued that both measures provide only a rough indication of students' use of the tool. They do not give information about 
whether the visualization of participation was meaningful for students, whether they actually used the tool in a meaningful way, whether they focused their gaze on important aspects of the tool, or whether students comprehended the information displayed in the tool. Using other methods to measure use of the PT, such as eye-tracking, may shed more light on these questions (Bonito, 2000).

Duration of PT use was found to affect several aspects of the online collaborative process. First, duration of use had a significantly positive effect on awareness of participation as expected (Dillenbourg, 1999): students who used the tool longer reported higher levels of awareness of participation. Furthermore, duration of use also affected student participation in the collaborative process in a similar way: students who used the PT longer also participated more in the online discussions and the collaborative writing process. Moreover, participation was more equal in groups that displayed the PT on their screen longer. Finally, we found a significant effect of duration of use and coordination and regulation of the relational space: students who used the PT longer, discussed more about the way their group was collaborating. No effect of duration of use on group performance was found however. This might be due to the fact that factors such as the interaction between students during the collaboration (Erkens \& Janssen, 2008; Janssen, Erkens, \& Kanselaar, 2007) and student characteristics (Jermann \& Dillenbourg, 2008) have a greater impact on group performance than group awareness tools. Another explanation may lie in the fact that use of the PT affected students' participation in the online discussions. However, this effect is possibly due to the fact that students that used the PT longer also engaged more in coordination and regulation strategies. In other words, they discussed more about the way their group was functioning and how this could possibly be improved, but they did not discuss more about the task. It could be argued that the PT distracted these students somewhat from the task. This might explain why no effect of duration of PT use on group performance was found. On the 
other hand, additional analyses showed a negative effect of duration of PT use on off-task behavior, meaning that when students used the PT longer, they engaged in less off-task behavior. This mirrors a similar finding by Janssen, Erkens, Kanselaar et al. (2007). Thus, although use of the PT might increase regulation of the relational space in favor of activities in the content space, this does not necessarily mean use of the PT increases off-task behavior. Further research is therefore needed to investigate how the PT affects collaborative activities and how these activities in turn affect group performance. It should also be noted that because group performance was measured at the group level, the statistical power to detect effects of familiarity was relatively small.

We performed mediation analyses to test the hypothesis that awareness of participation mediates the effect of the PT on online collaboration. The results only partially confirm that awareness of participation might be a mediating variable that explains how using the PT affects online collaboration. We found that awareness of group members' participation, partially mediates the effect of duration of PT use on students’ participation during the online discussions and the collaborative process. This means that part of the effect of the PT on student participation can be explained by the fact that the PT raises students' awareness of participation, which in turn leads to more active student participation during the online collaboration. Our study therefore partially confirms the ideas articulated by several authors (Kirschner et al., 2008) that group awareness tools such as the PT may affect online collaboration by raising students' group awareness, in this case awareness of participation.

It should be noted that group size may have influenced the results of our study (Weinberger, Ertl, Fischer, \& Mandl, 2005). This study used groups with three or four members. In smaller groups the obligation to participate is higher, lack of participation can therefore be noticed more easily . Therefore, if larger groups had been used in this study, the results might have been different. In large groups, the PT could possibly have a greater 
impact on equality of participation. Similarly, in larger groups it is more difficult to know what group members are doing and which group members are participating too little. Therefore, under these circumstances the PT could possibly have a greater impact on awareness of participation. In the future research, it should be examined whether group size influences the effects of visualization of participation.

The nature of the collaborative task used in this study may also have affected our results. This study used an inquiry group task, for which a high level of collaboration and equal participation was necessary to perform well. However, due to the large amount of information that had to be read by the students, students often divided the work among themselves. This may more have resembled working on a cooperative task than a collaborative task . For cooperative tasks (e.g., Jigsaw), equal participation is not always necessary. Possibly, the effects of the PT will be different for tasks that explicitly stimulate division of labor (e.g., cooperation) than for tasks that require simultaneous problem-solving (e.g., collaboration).

The careful reader will have noticed a discrepancy between how student participation was operationalized in the visualization of the PT and how this was operationalized in the study. The PT used number of keystrokes typed in the chat-tool as a measure of student participation. In our analyses we however used number of dialogue acts typed as a measure of student participation. This was done because during chat conversations some users only send one proposition per message, while other users type multiple sentences which combine several propositions. Chat messages were therefore segmented into smaller segments which had only one communicative function (i.e., a dialogue act). However, if the aim of the PT is to stimulate students to contribute more dialogue acts to the discussion instead of merely increasing the number of keystrokes typed, it would probably be better to also use number of dialogue acts sent as a basis for visualizing student participation. This would necessitate an 
online immediate segmentation of chat messages into dialogue acts. Recent developments in the field of automatic coding of collaborative dialogue have made this a real possibility however .

Another way to improve the PT would be to include so-called mirroring information in the visualization. A mirroring tool provides students with a visualization of the "difference" between what they have done during the interaction and what they should have done (in order to reach an efficient collaboration). By not only providing awareness information, but also normative information about students’ behavior, students may be further motivated to contribute to the collaboration process.

This study shows that it is important that research not only examines the effects of group awareness tools in (quasi-)experimental designs, but also takes into account whether students use group awareness tools and how they use these tools. Other studies (Clarebout \& Elen, 2006; Jiang et al., 2009) and the current study demonstrate that students' use of a tool affects the impact of the tool on their collaboration process. It is therefore important that future research takes this into account. Moreover, future research should try to examine tool use not only using log file analyses, but also using other methods such as eye-tracking (Molinari et al., 2009; Sangin et al., 2008; Van Gog et al., 2009) or stimulated recall interviews with students to understand their motives for using the tool, whether or not they understood the tool and whether they valued the tool (Beers, Boshuizen, Kirschner, Gijselaers, \& Westendorp, 2008).

This study shows that the effectiveness of group awareness tools depends on how students use such a tool. In this study, students could decide for themselves whether they used the tool or not. A new line of research could then focus on enhancing the effectiveness of group awareness tools by coercing or scripting its use. Another approach to further enhance the effectiveness of group awareness tools may be to employ attention guidance . 
This means that the group awareness tool also shows the eye movements of a model or expert while working with the tool, which may help students to focus on the important aspects of the tool. Whichever direction future research takes, we are confident group awareness tools will remain an important way to enhance the effectiveness of CSCL.

\section{REFERENCES}

Adrianson, L. (2001). Gender and computer-mediated communication: Group processes in problem solving. Computers in Human Behavior, 17, 71-94.

Ainsworth, S. (2006). DeFT: A conceptual framework for considering learning with multiple representations. Learning and Instruction, 16, 183-198.

Baker, K., Greenberg, S., \& Gutwin, C. (2001). Heuristic evaluation of groupware based on the mechanics of collaboration. Paper presented at the Engineering for HumanComputer Interaction: 8th IFIP International Conference, EHCI 2001, Toronto, Canada.

Baron, R. M., \& Kenny, D. A. (1986). The moderator-mediator variable distinction in social psychological research: Conceptual, strategical, and statistical considerations. Journal of Personality and Social Psychology, 51, 1173-1182.

Barron, B. (2003). When smart groups fail. Journal of the Learning Sciences, 12, 307-359.

Bødker, S., \& Christiansen, E. (2006). Computer support for social awareness in flexible work. Computer Supported Cooperative Work (CSCW), 15, 1-28.

Bonito, J. A. (2000). The effect of contributing substantively on perceptions of participation. Small Group Research, 31, 528-553.

Buder, J., \& Bodemer, D. (2008). Supporting controversial CSCL discussions with augmented group awareness tools. International Journal of Computer-Supported Collaborative Learning, 3, 123-139.

Butler, D. L., \& Winne, P. H. (1995). Feedback and self-regulated learning: A theoretical synthesis. Review of Educational Research, 65, 245-281.

Clarebout, G., \& Elen, J. (2006). Tool use in computer-based learning environments: Towards a research framework. Computers in Human Behavior, 22, 389-411.

Cohen, E. G. (1994). Restructuring the classroom: Conditions for productive small groups. Review of Educational Research, 64, 1-35.

Cress, U. (2008). The need for considering multilevel analysis in CSCL research: An appeal for the use of more advanced statistical methods. International Journal of ComputerSupported Collaborative Learning, 3, 69-84.

Dillenbourg, P. (1999). Introduction: What do you mean by "Collaborative Learning"? In P. Dillenbourg (Ed.), Collaborative learning: Cognitive and computational approaches (pp. 1-19). Amsterdam: Pergamon.

Dillenbourg, P., Baker, M., Blaye, A., \& O'Malley, C. (1996). The evolution of research on collaborative learning. In H. Spada \& P. Reimann (Eds.), Learning in humans and machine: Towards an interdisciplinary learning science (pp. 189-211). Oxford: Elsevier.

Dourish, P., \& Bellotti, V. (1992). Awareness and coordination in shared work spaces. Paper presented at the ACM Conference on Computer Supported Cooperative Work (CSCW'92), Toronto, Canada. 
Ellis, C. A., Gibbs, S. J., \& Rein, G. (1992). Groupware: Some issues and experiences. In D. Marca \& G. Bock (Eds.), Groupware: Software for computer-supported cooperative work (pp. 23-43). Los Alamitos, CA: IEEE Computer Society Press.

Engelmann, T., Dehler, J., Bodemer, D., \& Buder, J. (2009). Knowledge awareness in CSCL: A psychological perspective. Computers in Human Behavior, 25, 949-960.

Erkens, G. (2005). Multiple Episode Protocol Analysis (MEPA). Version 4.10. Utrecht University, The Netherlands.

Erkens, G., \& Janssen, J. (2008). Automatic coding of online collaboration protocols. International Journal of Computer Supported Collaborative Learning (ijCSCL), 3, 447-470.

Erkens, G., Jaspers, J., Prangsma, M., \& Kanselaar, G. (2005). Coordination processes in computer supported collaborative writing. Computers in Human Behavior, 21, 463486.

Fischer, F., Bruhn, J., Gräsel, C., \& Mandl, H. (2002). Fostering collaborative knowledge construction with visualization tools. Learning and Instruction, 12, 213-232.

Fjermestad, J. (2004). An analysis of communication mode in group support systems research. Decision Support Systems, 37, 239-263.

Gutwin, C., \& Greenberg, S. (2002). A descriptive framework of workspace awareness for real-time groupware. Computer Supported Cooperative Work (CSCW), 11, 411-446.

Gutwin, C., \& Greenberg, S. (2004). The importance of awareness for team cognition in distributed collaboration. In E. Salas \& S. M. Fiore (Eds.), Team cognition:

Understanding the factors that drive processes and performance (pp. 177-201). Washington: APA Press.

Gutwin, C., Stark, G., \& Greenberg, S. (1995). Support for workspace awareness in educational groupware. In J. L. Schnase \& E. L. Cunnius (Eds.), The first international conference on Computer support for collaborative learning (pp. 147156). Mahwah, NJ: Lawrence Erlbaum Associates Inc.

Hobman, E. V., Bordia, P., Irmer, B., \& Chang, A. (2002). The expression of conflict in computer-mediated and face-to-face groups. Small Group Research, 33, 439-465.

Howell-Richardson, C., \& Mellar, H. (1996). A methodology for the analysis of patterns of participation within computer mediated communication courses. Instructional Science, 24, 47-69.

Janssen, J., Erkens, G., \& Kanselaar, G. (2007). Visualization of agreement and discussion processes during computer-supported collaborative learning. Computers in Human Behavior, 23, 1105-1125.

Janssen, J., Erkens, G., Kanselaar, G., \& Jaspers, J. (2007). Visualization of participation: Does it contribute to successful computer-supported collaborative learning? Computers \& Education, 49, 1037-1065.

Jermann, P., \& Dillenbourg, P. (2008). Group mirrors to support interaction regulation in collaborative problem solving. Computers \& Education, 51, 279-296.

Jiang, L., Elen, J., \& Clarebout, G. (2009). The relationships between learner variables, toolusage behaviour and performance. Computers in Human Behavior, 25, 501-509.

Keller, T., \& Tergan, S. O. (2005). Visualizing knowledge and information: An introduction. In S. O. Tergan \& T. Keller (Eds.), Knowledge and information visualization: Searching for synergies (Vol. 3426, pp. 1-23). Berlin: Springer-Verlag Berlin.

Kenny, D. A., Kashy, D. A., \& Cook, W. L. (2006). Dyadic data analysis. New York/London: The Guilford Press.

Kenny, D. A., Mannetti, L., Pierro, A., Livi, S., \& Kashy, D. A. (2002). The statistical analysis of data from small groups. Journal of Personality and Social Psychology, 83, 126-137. 
Kirschner, F., Paas, F., \& Kirschner, P. A. (2009). A cognitive load approach to collaborative learning: United brains from complex learning. Educational Psychology Review, 21, 31-42.

Kirschner, P. A., Beers, P. J., Boshuizen, H. P. A., \& Gijselaers, W. H. (2008). Coercing shared knowledge in collaborative learning environments. Computers in Human Behavior, 24, 403-420.

Kirschner, P. A., Strijbos, J. W., Kreijns, K., \& Beers, P. J. (2004). Designing electronic collaborative learning environments. Educational Technology Research and Development, 52(3), 47-66.

Kreijns, K., \& Kirschner, P. A. (2001). The social affordances of computer-supported collaborative learning environments. Paper presented at the 31st Annual Frontiers in Education Conference, Reno, NV.

Kreijns, K., Kirschner, P. A., \& Jochems, W. (2003). Identifying the pitfalls for social interaction in computer-supported collaborative learning environments: A review of the research. Computers in Human Behavior, 19, 335-353.

Lipponen, L., Rahikainen, M., Lallimo, J., \& Hakkarainen, K. (2003). Patterns of participation and discourse in elementary students' computer-supported collaborative learning. Learning and Instruction, 13, 487-509.

MacKinnon, D. P., Fairchild, A. J., \& Fritz, M. S. (2007). Mediation analysis. Annual Review of Psychology, 58, 593-614.

Manlove, S., Lazonder, A. W., \& De Jong, T. (2006). Regulative support for collaborative scientific inquiry learning. Journal of Computer Assisted Learning, 22, 87-98.

McGrath, J. E. (1991). Time, interaction, and performance (TIP). Small Group Research, 22, 147-174.

Mendoza-Chapa, S., Romero-Salcedo, M., \& Oktaba, H. (2000). Group awareness support in collaborative writing systems. Paper presented at the 6th International Workshop on Groupware (CRIWG'00), Madeira, Portugal.

Michinov, N., \& Primois, C. (2005). Improving productivity and creativity in online groups through social comparison process: New evidence for asynchronous electronic brainstorming. Computers in Human Behavior, 21, 11-28.

Molinari, G., Sangin, M., Dillenbourg, P., \& Nussli, M. A. (2009). Knowledge interdependence with the partner, accuracy of mutual knowledge model and computer-supported collaborative learning. European Journal of Psychology of Education, 24, 129-144.

Phielix, C., Prins, F. J., \& Kirschner, P. A. (2010). Awareness of group performance in a CSCL-environment: Effects of peer feedback and reflection. Computers in Human Behavior, 26, 151-161.

Romero-Salcedo, M., Osuna-Gómez, C., A., Sheremetov, L., Villa, L., Morales, C., Rocha, L., et al. (2004). Study and analysis of workspace awareness in CDebate: A groupware application for collaborative debates. Interacting with Computers, 16, 657681.

Salomon, G., \& Globerson, T. (1989). When teams do not function the way they ought to. International Journal of Educational Research, 13, 89-99.

Sangin, M., Molinari, G., Nüssli, M. A., \& Dillenbourg, P. (2008). How learners use awareness cues about their peer's knowledge? Insights from synchronized eyetracking data. In P. A. Kirschner, F. Prins, V. Jonker \& G. Kanselaar (Eds.), Cre8ting a learning world: Proceedings of the 8th International Conference of the Learning Sciences (Vol. 2, pp. 287-294). Utrecht, The Netherlands: International Society of the Learning Sciences. 
Savicki, V., Kelley, M., \& Ammon, B. (2002). Effects of training on computer-mediated communication in single or mixed gender small task groups. Computers in Human Behavior, 18(3), 257-270.

Schmidt, K. (2002). The problem with 'Awareness': Introductory remarks on 'Awareness in CSCW'. Computer Supported Cooperative Work (CSCW), 11, 285-298.

Shepperd, J. A. (1993). Productivity loss in performance groups: A motivation analysis. Psychological Bulletin, 113, 67-81.

Shrout, P. E., \& Bolger, N. (2002). Mediation in experimental and nonexperimental studies: New procedures and recommendations. Psychological Methods, 7, 422-445.

Slof, B., Erkens, G., Kirschner, P. A., Jaspers, J. G. M., \& Janssen, J. (2010). Guiding students' online complex learning-task behavior through representational scripting. Computers in Human Behavior, 26, 927-939.

Straus, S. G. (1997). Technology, group process, and group outcomes: Testing the connections in computer-mediated and face-to-face groups. Human-Computer Interaction, 12, 227-266.

Strijbos, J. W., Martens, R. L., \& Jochems, W. M. G. (2004). Designing for interaction: Six steps to designing computer-supported group-based learning. Computers \& Education, 42, 403-424.

Sweller, J., \& Chandler, P. (1994). Why some material is difficult to learn. Cognition and Instruction, 12, 185-233.

Teasley, S. D., \& Roschelle, J. (1993). Constructing a joint problem space: The computer as a tool for sharing knowledge. In S. P. Lajoie (Ed.), Computers as cognitive tools: Technology in education (pp. 229-258). Hillsdale, NJ, England: Lawrence Erlbaum Associates, Inc.

Van Bruggen, J. M., Kirschner, P. A., \& Jochems, W. (2002). External representation of argumentation in CSCL and the management of cognitive load. Learning and Instruction, 12, 121-138.

Van Gog, T., Kester, L., Nievelstein, F., Giesbers, B., \& Paas, F. (2009). Uncovering cognitive processes: Different techniques that can contribute to cognitive load research and instruction. Computers in Human Behavior, 25, 325-331.

Ware, C. (2005). Visual queries: The foundation of visual thinking In S. O. Tergan \& T. Keller (Eds.), Knowledge and information visualization: Searching for synergies (Vol. 3426, pp. 27-35). Berlin: Springer-Verlag Berlin.

Webb, N. M. (1995). Group collaboration in assessment: Multiple objectives, processes, and outcomes. Educational Evaluation and Policy Analysis, 17, 239-261.

Webb, N. M., Nemer, K. M., \& Zuniga, S. (2002). Short circuits or superconductors? Effects of group composition on high-achieving students' science assessment performance. American Educational Research Journal, 39, 943-989.

Webb, N. M., \& Palincsar, A. S. (1996). Group processes in the classroom. In D. C. Berliner (Ed.), Handbook of educational psychology (pp. 841-873). New York: Simon \& Schuster Macmillan.

Weinberger, A., Ertl, B., Fischer, F., \& Mandl, H. (2005). Epistemic and social scripts in computer-supported collaborative learning. Instructional Science, 33, 1-30.

Yager, S., Johnson, R. T., Johnson, D. W., \& Snider, B. (1986). The impact of group processing on achievement in cooperative learning groups. Journal of Social Psychology, 126, 389-397.

Zumbach, J., Hillers, A., \& Reimann, P. (2004). Distributed problem-based learning: The use of feedback mechanisms in online learning. In T. S. Roberts (Ed.), Online collaborative learning: Theory and practice (pp. 86-102). Hershey, PA: Idea Group, Inc. 
Zumbach, J., \& Reimann, P. (2003). Influence of feedback on distributed problem based learning: Enhancing online communities in group functioning and well-being. In B. Wasson, S. Ludvigsen \& U. Hoppe (Eds.), Designing for change in networked learning environments (pp. 219-228). Dordrecht, The Netherlands: Kluwer. 
Figure 1

Screenshot of the Participation-tool

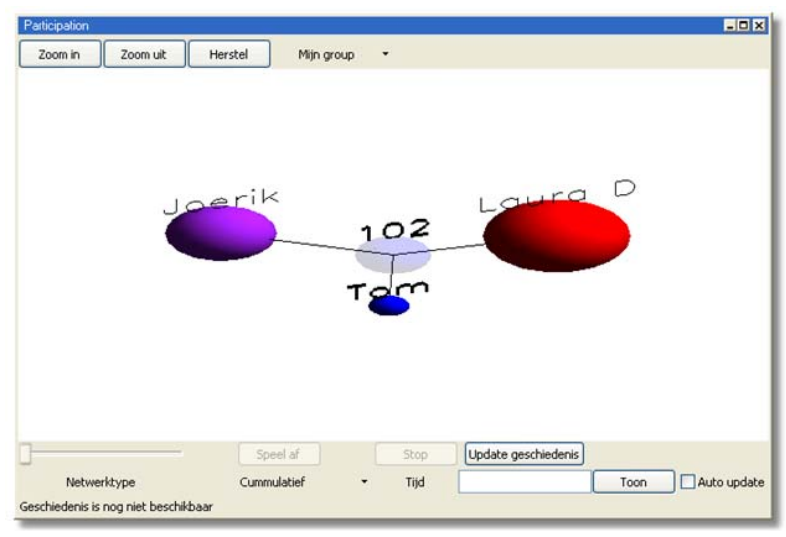


Figure 2

Screenshot of VCRI




Figure 3

Development of intensity of PT use and duration of PT use during the eight weeks of the study.

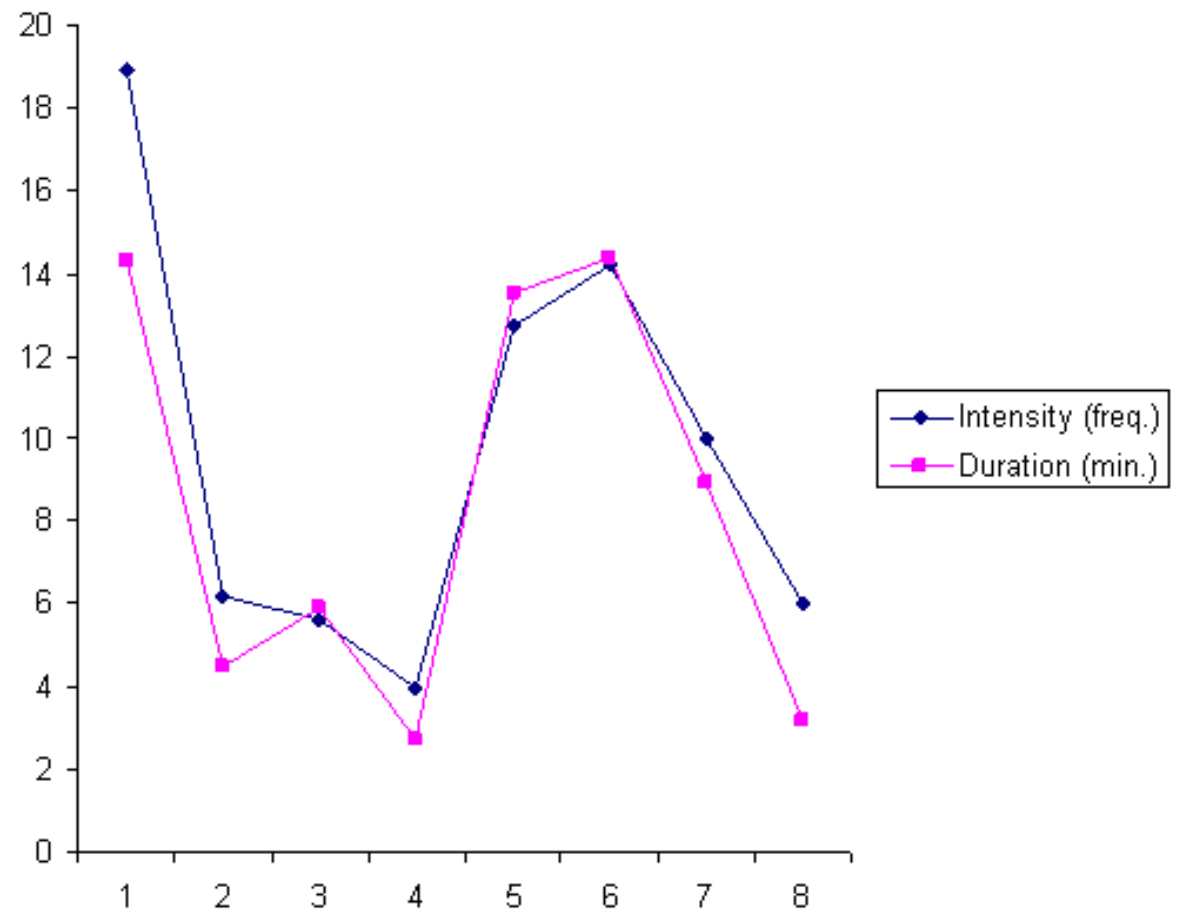


Figure 4

Graphical representation of mediation analyses.

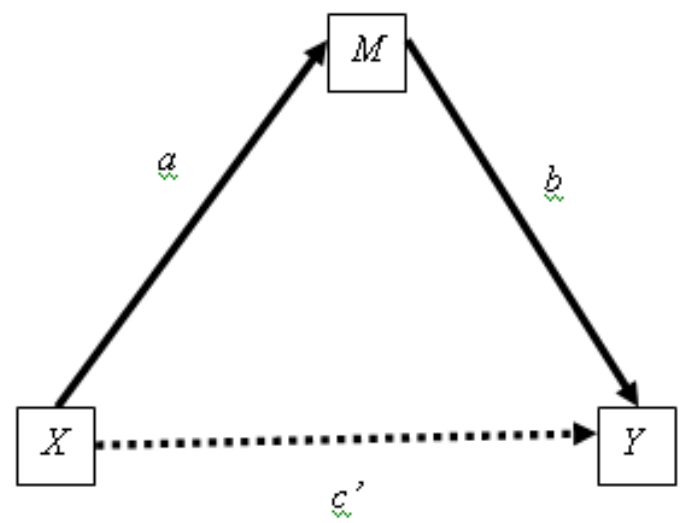




\section{Using Group Awareness Tools 44}

Table 1

Means, standard deviations, and intercorrelations of variables used in the study.

\begin{tabular}{|c|c|c|c|c|c|c|c|c|c|c|c|c|}
\hline & & $N$ & $M$ & $S D$ & 1 & 2 & 3 & 4 & 5 & 6 & 7 & 8 \\
\hline 1 & Intensity of PT use & 107 & 77.36 & 38.92 & - & $.23^{*}$ & .03 & -.08 & -.02 & -.02 & -.01 & -.04 \\
\hline 2 & Overall duration of PT use & 107 & 66.82 & 43.36 & & - & $.30^{* *}$ & $.36^{* *}$ & $.32^{* *}$ & $-.36^{*}$ & $.25^{* *}$ & .27 \\
\hline 3 & Awareness of participation & 107 & 3.21 & 0.67 & & & - & $.33^{* *}$ & $.32^{* *}$ & .06 & $.23^{*}$ & .28 \\
\hline 4 & Participation chat discussion & 107 & 294.92 & 184.46 & & & & - & .17 & .12 & $.83^{* *}$ & .06 \\
\hline 5 & Participation cowriter & 107 & 6816.50 & 1938.87 & & & & & - & -.31 & .17 & .17 \\
\hline 6 & Equality of participation ${ }^{\mathrm{a}}$ & 35 & .15 & .07 & & & & & & - & .10 & .02 \\
\hline 7 & Group processing & 107 & 19.52 & 15.44 & & & & & & & - & -.05 \\
\hline 8 & Group performance $^{a}$ & 35 & .58 & .10 & & & & & & & & - \\
\hline
\end{tabular}


Table 2

Estimates for random intercept multilevel model investigating the effect of intensity of PT use on awareness of participation $(N=107)$.

\begin{tabular}{lcc}
\hline & $\beta$ & $S E$ \\
\hline$\gamma_{00}=$ Intercept & 3.033 & 0.133 \\
$\beta_{1}=$ Intensity of PT use & 0.002 & 0.001
\end{tabular}

Variance

Group level

Individual level

Deviance

Decrease in deviance
$0.214 \quad 0.036$

$\begin{array}{ll}0.022 & 0.071\end{array}$

200.373

0.092 
Table 3

Estimates for random intercept multilevel model investigating the effect of duration of PT use on awareness of participation $(N=107)$.

\begin{tabular}{lcc}
\hline & $\beta$ & $S E$ \\
\hline$\gamma_{00}=$ Intercept & 2.974 & 0.135 \\
$\beta_{1}=$ Duration of PT use & $0.003^{*}$ & 0.002 \\
& & \\
Variance & & 0.037 \\
Group level & 0.222 & 0.064 \\
Individual level & 0.180 & \\
& & \\
Deviance & & \\
Decrease in deviance & & \\
\hline${ }^{*} p<.05$ & $7.198^{* *}$ & \\
${ }^{* *} p<.01$ & & \\
\end{tabular}


Table 4

Estimates for random intercept multilevel model investigating the effect of intensity of PT use on student participation in the online discussion $(N=107)$.

\begin{tabular}{lcc}
\hline & & \\
& & \\
\hline$\gamma_{00}=$ Intercept & 301.860 & 37.860 \\
$\beta_{1}=$ Intensity of PT use & -0.073 & 0.361 \\
Variance & & \\
Group level & 17642.950 & 2930.492 \\
Individual level & 17184.612 & 5650.845 \\
& & \\
Deviance & 1387.234 & \\
Decrease in deviance & 0.165 & \\
\hline
\end{tabular}


Table 5

Estimates for random intercept multilevel model investigating the effect of duration of PT use on student participation in the online discussion $(N=107)$.

\begin{tabular}{|c|c|c|}
\hline & $\beta$ & $S E$ \\
\hline$\gamma_{00}=$ Intercept & 197.803 & 37.122 \\
\hline$\beta_{1}=$ Duration of PT use & $1.463^{* *}$ & 0.425 \\
\hline \multicolumn{3}{|l|}{ Variance } \\
\hline Group level & 16038.421 & 2683.000 \\
\hline Individual level & 14454.387 & 4893.250 \\
\hline Deviance & 1375.670 & \\
\hline Decrease in deviance & $11.399^{* *}$ & \\
\hline
\end{tabular}


Table 6

Estimates for random intercept multilevel model investigating the effect of intensity of PT use on student participation in the Cowriter $(N=107)$.

\begin{tabular}{lcc}
\hline & $\beta$ & $S E$ \\
\hline$\gamma_{00}=$ Intercept & 6731.366 & 417.540 \\
$\beta_{1}=$ Intensity of PT use & 1.153 & 4.488 \\
Variance & & $0.48610^{6}$ \\
Group level & $2.87910^{6}$ & $0.49610^{6}$ \\
Individual level & $0.94310^{6}$ & \\
Deviance & & \\
Decrease in deviance & 1899.746 & \\
\hline
\end{tabular}


Table 7

Estimates for random intercept multilevel model investigating the effect of duration of PT use on student participation in the Cowriter $(N=107)$.

\begin{tabular}{lcc}
\hline & $\beta$ & $S E$ \\
\hline$\gamma_{00}=$ Intercept & 5930.745 & 360.124 \\
$\beta_{1}=$ Duration of PT use & $13.264^{* *}$ & 4.439 \\
Variance & & \\
Group level & $2.93810^{6}$ & $0.49710^{6}$ \\
Individual level & $0.48110^{6}$ & $0.40310^{6}$ \\
& & \\
Deviance & 1892.121 & \\
Decrease in deviance & $12.528^{* *}$ & \\
\hline$* 01$ & & \\
\hline
\end{tabular}


Table 8

Estimates for random intercept multilevel model investigating the effect of intensity of PT use on activities that coordinate and regulate the relational space $(N=107)$.

\begin{tabular}{lcc}
\hline & & $S E$ \\
\hline$\gamma_{00}=$ Intercept & 17.201 & 3.304 \\
$\beta_{1}=$ Intensity of PT use & 0.031 & 0.035 \\
Variance & & \\
Group level & 178.267 & 29.925 \\
Individual level & 61.912 & 30.938 \\
& & \\
Deviance & & \\
Decrease in deviance & 0.408 & \\
\hline
\end{tabular}


Table 9

Estimates for random intercept multilevel model investigating the effect of duration of PT use on activities that coordinate and regulate the relational space $(N=107)$.

\begin{tabular}{|c|c|c|}
\hline & $\beta$ & $S E$ \\
\hline$\gamma_{00}=$ Intercept & 12.691 & 3.099 \\
\hline$\beta_{1}=$ Duration of PT use & $0.103^{* *}$ & 0.037 \\
\hline \multicolumn{3}{|l|}{ Variance } \\
\hline Group level & 164.973 & 27.713 \\
\hline Individual level & 62.655 & 30.399 \\
\hline Deviance & 876.611 & \\
\hline Decrease in deviance & $2.743^{*}$ & \\
\hline \multicolumn{3}{|l|}{${ }^{*} p<.05$} \\
\hline${ }^{* *} p<.01$ & & \\
\hline
\end{tabular}

